\title{
Aqueous zinc-organic polymer battery with a high rate performance and long lifetime
}

\author{
Bernhard Häupler ${ }^{1,2}$, Carsten Rössel ${ }^{1}$, Almut M Schwenke ${ }^{1}$, Jan Winsberg ${ }^{1,2}$, Daniel Schmidt ${ }^{1,2}$, \\ Andreas Wild ${ }^{1,2}$ and Ulrich S Schubert ${ }^{1,2}$
}

A novel redox-active polymer based on a 9,10-di(1,3-dithiol-2-ylidene)-9,10-dihydroanthracene (exTTF) system in combination with a conjugated backbone was synthesized via rhodium (Rh)-catalyzed polymerization of 2-ethynyl(exTTF), leading to polymers with low polydispersities. Composite electrodes containing this polymer exhibited chemically reversible two-electron oxidation in aqueous media. The application of these electrodes as active cathode materials in hybrid zinc-organic batteries using an aqueous electrolyte enabled the production of air-stable charge storage systems with a theoretical capacity of $133 \mathrm{mAh} \mathrm{g}^{-1}$. These batteries featured high performance, charge/discharge rates of up to $120 \mathrm{C}(30 \mathrm{~s})$ and an ultra-long lifetime, of over 10000 charge/discharge cycles (accompanied by a minor capacity loss of $14 \%$ ). Finally, the polymer was compared with its nonconjugated derivative, revealing the positive influence of the conjugated backbone on the material activity owing to improved electron transfer within the polymer chain.

NPG Asia Materials (2016) 8, e283; doi:10.1038/am.2016.82; published online 1 July 2016

\section{INTRODUCTION}

The application of organic redox-active compounds, instead of metals and their alloys, as active materials in both the anode and the cathode of secondary batteries has certain advantages such as low toxicity, flexibility and being light in weight. ${ }^{1,2}$ Organic compounds are synthesized in low-temperature processes and consist of naturally abundant elements, such as carbon, nitrogen, oxygen and/or sulfur, allowing residual-free disposal and energy generation from renewable resources; this consequently leads to a low carbon footprint. ${ }^{3}$ The diversity of organic chemistry provides a vast number of possible redox-active structures whose redox potential can be tailored by the introduction of electron donating/withdrawing groups. ${ }^{4}$ A large number of different redox-active compounds, such as organic radicals, ${ }^{5}$ carbonyls ${ }^{6}$ and sulfur-containing compounds, have been successfully applied as active materials in secondary batteries. ${ }^{7}$ However, the decisive disadvantage of their utilization is their solubility in the electrolyte, leading to large capacity decay. One of the most promising approaches to overcome this drawback is the introduction of redox-active species into a polymeric backbone. ${ }^{8-13}$ This approach decreases the solubility and enables electronic interactions, such as electron hopping processes, between the single redox-active units, allowing electron transport within the polymer chain. ${ }^{14}$

Most organic electrode materials are utilized as cathodes, and elemental lithium, sodium or their intercalation materials serve as anodes, whose low redox potentials lead to high energy densities; however, these require the use of organic solvents as the electrolyte that is associated with several drawbacks. The major problem is safety that is attributed to the flammability of the organic electrolyte and the thermal runaway reactions caused by the reactivity of the electrode materials. In addition, the cost of lithium or sodium-based secondary battery production is quite high owing to the requirement for strictly dry production environments and the high cost of dry organic solvents and lithium or sodium salts. In addition, the poor ionic conductivity of organic solvents requires a special electrode design to enable high power and energy densities.

In contrast, the use of aqueous electrolytes is a potential alternative and overcomes several disadvantages of organic electrolytes. Water is inexpensive, safe and environmentally friendly. It allows for a simple battery assembly process and features a higher ionic conductivity by two orders of magnitude compared with organic electrolytes, enabling a higher rate performance. ${ }^{15}$ However, the electrochemical stability window of water is limited by the electrolysis of water and, therefore, it is narrower than those of organic electrolytes. In addition, the stable operation window strongly depends on the $\mathrm{pH}$ of the aqueous electrolyte $^{16}$ and the choice of the current collector material; thus, the operation window is a result of the activation overpotential.

Furthermore, the organic redox-active groups, which are mandatory for charge storage, have to be chosen carefully because all of the redox states must be stable in the presence of water and also sometimes at high/low $\mathrm{pH}$ values. ${ }^{17}$ For a one-electron redox process, in general, a

${ }^{1}$ Laboratory of Organic and Macromolecular Chemistry (IOMC), Friedrich Schiller University Jena, Jena, Germany and ${ }^{2}$ Center for Energy and Environmental Chemistry Jena (CEEC Jena), Friedrich Schiller University Jena, Jena, Germany

Correspondence: Dr Professor US Schubert, Laboratory of Organic and Macromolecular Chemistry (IOMC), Friedrich Schiller University Jena, Humboldtstraße 10, 07743 Jena, Germany.

E-mail: ulrich.schubert@uni-jena.de

Received 19 February 2016; revised 6 April 2016; accepted 8 April 2016 
stable organic radical is preferred because a stable organic cation/anion is formed upon oxidation/reduction. If an uncharged compound is applied during a one-electron oxidation/reduction process, it would form a radical cation/anion that is highly reactive and tends to undergo irreversible side reactions, leading to a capacity drop in the battery device. ${ }^{18}$ The presence of a two-electron redox process requires a neutral redox-active molecule that forms a stable dication/dianion during oxidation/reduction.

Recently, we focused on polymers based on anthraquinone derivatives ${ }^{10}$ and their application as active electrode materials. We specifically focused on materials that undergo a single two-electron redox reaction, leading to a narrow charge/discharge voltage accompanied by a comparably high theoretical capacity. ${ }^{12}$ In particular, the $\pi$-extended tetrathiafulvalene system, namely 9,10-di(1,3-dithiol-2ylidene)-9,10-dihydroanthracene (exTTF), exhibited a suitable redox potential for the two-electron oxidation as applied in aqueous electrolyte. Herein, we report a novel poly(acetylene)-based polymer with exTTF moieties and its application as a cathode-active material in hybrid zinc-organic secondary batteries with a high rate performance and ultra-long life cycle.

\section{EXPERIMENTAL PROCEDURES}

\section{Methods}

Tetrahydrofuran was dried with a PureSolv-EN Solvent Purification System (Innovative Technology, Amesbury, MA, USA). Triethylamine was distilled over potassium hydroxide under argon atmosphere and stored over molecular sieves. Anhydrous $\mathrm{N}, \mathrm{N}$-dimethylformamide (DMF), $N$-methyl-2-pyrrolidone (NMP) and acetonitrile were purchased from Acros Organics (Geel, Belgium). All other starting materials were purchased from commercial sources and were used as obtained. Poly(vinylexTTF) was synthesized according to a previously published procedure. ${ }^{12}$ The reactions were monitored using thin-layer chromatography on $0.2 \mathrm{~mm}$ Merck silica gel plates (Darmstadt, Germany; 60 F254). Column chromatography was performed on silica gel 60 (Macherey-Nagel, Düren, Germany; 40 to $63 \mu \mathrm{m}$ ). ${ }^{1} \mathrm{H}$ and ${ }^{13} \mathrm{C}$ nuclear magnetic resonance (NMR) spectra were recorded on a Bruker AC 300 (Rheinstetten, Germany; $300 \mathrm{MHz}, 75 \mathrm{mHz}$ ) spectrometer at $298 \mathrm{~K}$. Chemical shifts are reported in parts per million (p.p.m., $\delta$ scale) relative to the residual signal of the deuterated solvent. Elemental analyses were carried out using a Vario ELIII Elementar Euro and an EA-HekaTech (Hanau, Germany). Cyclic voltammetry and galvanostatic experiments were performed using a Bio-Logic VMP 3 potentiostat (Claix, France) at room temperature. Size-exclusion chromatography was performed on an Agilent 1200 series system (Santa Clara, CA, USA; degasser, PSS; pump, G1310A; auto sampler, G1329A; oven, Techlab; DAD detector, G1315D; RI detector, G1362A; eluent, DMAc+0.21\% LiCl, $1 \mathrm{ml} \mathrm{min}^{-1}$; temperature, $40^{\circ} \mathrm{C}$; column, PSS GRAM guard/1000/30 ̊). Scanning electron microscopy imaging was performed with a LEO 1530 Gemini microscope (Zeiss, Jena, Germany) utilizing an InLense detector.

\section{Synthesis of 2-((trimethylsilyl)ethynyl)anthraquinone (2)}

2-((Trimethylsilyl)ethynyl)anthraquinone was synthesized according to a modified method from the literature. ${ }^{19}$ 2-Chloroanthraquinone (500 mg, $2.06 \mathrm{mmol}$ ), bis(triphenylphosphine)palladium(II) dichloride (28 $\mathrm{mg}, 0.041 \mathrm{mmol})$ and copper(I) iodide $(7.8 \mathrm{mg}, 0.04 \mathrm{~mol})$ were dissolved in tetrahydrofuran/triethylamine $1 / 1 \mathrm{v} / \mathrm{v}(6.1 \mathrm{ml})$ under argon atmosphere. Subsequently, trimethylsilylacetylene $(160 \mu \mathrm{l}$, $2.3 \mathrm{mmol}$ ) was added, and the reaction mixture was stirred at $80^{\circ} \mathrm{C}$ for $4 \mathrm{~h}$. After cooling to room temperature, chloroform was added $(25 \mathrm{ml})$, and the reaction mixture was extracted with saturated ammonium chloride solution $(25 \mathrm{ml})$, water $(25 \mathrm{ml})$ and brine $(25 \mathrm{ml})$, dried over $\mathrm{MgSO}_{4}$, filtered and evaporated under reduced pressure. The obtained crude product was purified by column chromatography $\left(\mathrm{CHCl}_{3} / n\right.$-hexane $\left.6 / 1 \mathrm{v} / \mathrm{v}\right)$ and resulted in $514 \mathrm{mg}$ $(82 \%)$ of $2-(($ trimethylsilyl)ethynyl)anthraquinone as a red powder. ${ }^{1} \mathrm{H}$ NMR $\left(\mathrm{CDCl}_{3}, 300 \mathrm{MHz}\right.$, p.p.m.): $\delta 8.31$ (Ph, 4H), $7.82(\mathrm{Ph}, 3 \mathrm{H})$, $0.30\left(\mathrm{CH}_{3}, 9 \mathrm{H}\right) .{ }^{13} \mathrm{C} \mathrm{NMR}\left(\mathrm{CDCl}_{3}, 75 \mathrm{MHz}\right.$, p.p.m.): $\delta$ 182.5, 137.3, $137.0,134.6,134.5,134.4,133.6,133.5,132.6,130.8,129.5,129.2$, $127.5,127.4,103.4,100.3,0.19,0.00,-0.19$. Analysis calculated for $\mathrm{C}_{19} \mathrm{H}_{16} \mathrm{O}_{2} \mathrm{Si}$ : C, 75.0; H, 5.3\%. Found: C, 74.9; H, 5.2\%.

\section{Synthesis of 2-ethynylanthraquinone (3)}

2-((Trimethylsilyl)ethynyl)anthraquinone (2) (400 mg, $1.32 \mathrm{mmol})$ was dissolved in a mixture of acetone and methanol $2 / 1 \mathrm{v} / \mathrm{v}(12 \mathrm{ml})$, and sodium hydroxide was added $(52.6 \mathrm{mg}, 1.32 \mathrm{mmol}$ ). The mixture was stirred for $3 \mathrm{~h}$ at room temperature. Then, $25 \mathrm{ml}$ chloroform was added, and the organic solution was extracted with a saturated ammonium chloride solution $(25 \mathrm{ml})$, water $(25 \mathrm{ml})$ and brine $(25 \mathrm{ml})$, dried over $\mathrm{MgSO}_{4}$, filtered and evaporated under reduced pressure. The obtained crude product was purified by column chromatography $\left(\mathrm{CHCl}_{3} / n\right.$-hexane $\left.6 / 1 \mathrm{v} / \mathrm{v}\right)$ and resulted in $371 \mathrm{mg}$ (93\%) 2-ethynylanthraquinone as a brown powder. ${ }^{1} \mathrm{H} \mathrm{NMR}\left(\mathrm{CDCl}_{3}\right.$, $300 \mathrm{MHz}$, p.p.m.): $\delta 8.32(\mathrm{Ph}, 4 \mathrm{H}), 7.83(\mathrm{Ph}, 3 \mathrm{H}), 3.37(\mathrm{CH}, 1 \mathrm{H}) .{ }^{13} \mathrm{C}$ $\mathrm{NMR}\left(\mathrm{CDCl}_{3}, 75 \mathrm{MHz}\right.$, p.p.m.): $\delta 182.8,137.5,134.8,134.7,133.9$, $133.8,133.3,131.3,128.7,127.8,127.5,82.4,82.3$. Analysis calculated for $\mathrm{C}_{16} \mathrm{H}_{8} \mathrm{O}_{2}$ : C, $82.8 ; \mathrm{H}, 3.5 \%$. Found: $\mathrm{C}, 82.7 ; \mathrm{H}, 3.4 \%$.

\section{Synthesis of 2,2'-(2-ethynylanthracene-9,10-diylidene) bis(1,3-} dithiole) (4)

Dimethyl-1,3-dithiol-2-ylphosphonate $\quad(733 \mathrm{mg}, \quad 3.45 \mathrm{mmol}$ ) was dissolved in $10 \mathrm{ml}$ tetrahydrofuran under argon atmosphere, and the reaction mixture was cooled to $-78^{\circ} \mathrm{C}$. A $2.5 \mathrm{M}$ solution of $n$-butyllithium in $n$-hexane $(1.50 \mathrm{ml}, 3.75 \mathrm{mmol})$ was added dropwise to the reaction mixture within $5 \mathrm{~min}$. The mixture was stirred at $-78^{\circ} \mathrm{C}$ for $2 \mathrm{~h}$. To the reaction mixture, a solution of 2-ethynylanthraquinone $(3)(352 \mathrm{mg}, 1.50 \mathrm{mmol})$ in $11.5 \mathrm{ml}$ tetrahydrofuran was added dropwise at $-78^{\circ} \mathrm{C}$, and the reaction mixture was stirred for $18 \mathrm{~h}$ at room temperature. Ethyl acetate $(50 \mathrm{ml})$ was added to the reaction mixture and extracted twice with water $(35 \mathrm{ml})$ and once with brine $(20 \mathrm{ml})$. The organic layer was dried over sodium sulfate, filtered and concentrated under reduced pressure. The crude product was purified by column chromatography (silica gel; $n$-hexane: toluene, $1 / 1 \mathrm{v} / \mathrm{v})$ to yield $700 \mathrm{mg}(2.12 \mathrm{mmol}, 51 \%)$ of 4 as yellow powder. ${ }^{1} \mathrm{H}$ NMR $\left(\mathrm{CDCl}_{3}, 300 \mathrm{MHz}\right.$, p.p.m.): $\delta 7.82$ (d, $J_{1}=1.8 \mathrm{~Hz}$, $1 \mathrm{H}), 7.69(\mathrm{~m}, 2 \mathrm{H}), 7.51\left(\mathrm{dd}, J_{1}=1.8 \mathrm{~Hz}, J_{2}=8.1 \mathrm{~Hz} 1 \mathrm{H}\right), 7.40$

Table 1 An overview of the catalyst systems used for the polymerization of monomer 4 , and the characterization of the resulting polymers

\begin{tabular}{lccc}
\hline Catalysta & $M_{n}\left(\mathrm{~g} \mathrm{~mol}^{-1}\right)$ & $P D l^{\mathrm{b}}$ & Yield (\%) \\
\hline $\mathrm{Rh}(\mathrm{nbd}) \mathrm{BPh}_{4}$ & $3.1110^{3}$ & 1.36 & 78 \\
$\mathrm{Rh}_{2}(\mathrm{nbd})_{2} \mathrm{Cl}_{2}$ & $2.0810^{3}$ & 1.22 & 72 \\
$\mathrm{Rh}_{2}(\mathrm{nbd})_{2} \mathrm{Cl}_{2}^{\mathrm{c}}$ & $3.1310^{3}$ & 1.19 & 81 \\
$\mathrm{Rh}_{2}(\mathrm{nbd})_{2} \mathrm{Cl}_{2}^{\mathrm{d}}$ & $1.4710^{4}$ & 1.11 & 98 \\
\hline
\end{tabular}

Abbreviation: PDI, polydispersity index.

aPolymerization conditions: $N, N$-dimethylformamide (DMF), room temperature (RT), concentration $0.2 \mathrm{~mol} \mathrm{I}^{-1}, 5 \mathrm{~mol} \%$ rhodium (Rh) catalyst, $16 \mathrm{~h}$.

${ }^{b}$ Determined by size exclusion chromatography (DMAc, $0.21 \% \mathrm{LiCl}$, poly(styrene) standard). 0.1 Eq. triethylamine.

d0.055 Eq. triphenylphosphine, 0.055 eq. NaOMe and 0.5 eq. $N, N$-dimethylaminopyridine (DMAP). 
$\left(\mathrm{d}, J_{2}=8.1 \mathrm{~Hz}, 1 \mathrm{H}\right), 7.30(\mathrm{~m}, 2 \mathrm{H}), 6.33(\mathrm{~m}, 4 \mathrm{H}), 3.03(\mathrm{~s}, 1 \mathrm{H}) .{ }^{13} \mathrm{C}$ $\mathrm{NMR}\left(75 \mathrm{MHz}, \mathrm{CDCl}_{3}\right.$, p.p.m.): $\delta 35.02,129.4,128.3,126.0$, 124.8,119.2, 117.2, 117.1, 83.7, 77.1. Analysis calculated for $\mathrm{C}_{22} \mathrm{H}_{12} \mathrm{~S}_{4}$ : C $65.3 \%$ H $3.0 \%$ S $31.7 \%$. Found: C $65.2 \% \mathrm{H} \quad 2.9 \%$ S $31.7 \%$.

\section{General procedure for $\mathrm{Rh}$-catalyzed polymerizations of 4}

A solution consisting of $50 \mathrm{mg}(0.12 \mathrm{mmol})$ of 4 in $0.5 \mathrm{ml}$ DMF under argon atmosphere was added to a solution of the rhodium (Rh) catalyst system $(0.006 \mathrm{mmol} \mathrm{Rh}, 5 \mathrm{~mol} \%)$ in $0.11 \mathrm{ml} \mathrm{DMF}$. The mixture was stirred for $16 \mathrm{~h}$ at room temperature and was then precipitated in $50 \mathrm{ml}$ of acetonitrile. The polymer was collected by centrifugation and purified by reprecipitation from DMF to acetonitrile, followed by centrifugation and drying at $40^{\circ} \mathrm{C}$ under vacuum. The detailed polymer analysis can be found in Table 1. Analysis calculated for $\mathrm{C}_{22} \mathrm{H}_{12} \mathrm{~S}_{4}$ : C $65.3 \% \mathrm{H} 3.0 \% \mathrm{~S} 31.7 \%$. Found: C $65.2 \% \mathrm{H}$ $3.1 \%$ S $31.6 \%$.

\section{Electrochemical analysis}

A three-electrode setup was used (WE: glassy carbon disk (diameter $2 \mathrm{~mm}$ ); RE: $\mathrm{AgNO}_{3} / \mathrm{Ag}$ in $\mathrm{CH}_{3} \mathrm{CN}$ and $0.1 \mathrm{M} n-\mathrm{Bu}_{4} \mathrm{NPF}_{6}$ for organic electrolytes and $\mathrm{AgCl} / \mathrm{Ag}$ for aqueous electrolytes; $\mathrm{CE}$ : Pt wire for the solution-based experiments and a coiled Pt-wire for the electrodebased experiments) for cyclic voltammetry. The redox couple of ferrocenium/ferrocene $\left(\mathrm{Fc}^{+} / \mathrm{Fc}\right)$ was utilized as the internal reference for the organic electrolytes.

\section{Preparation of composite electrodes}

The electrodes were prepared by adding a solution of $\mathbf{5}$ and poly (vinylidene fluoride) (PVDF; Sigma-Aldrich, Munich, Germany) in NMP to multi-walled carbon nanotubes (MWCNTs; Sigma-Aldrich) as a conducting additive (ratio: $2 / 7 / 1$ and $1 / 1 / 0 \mathrm{~m} / \mathrm{m} / \mathrm{m} \mathrm{5/MWCNT/}$ PVDF). These materials were mixed in a mortar for $10 \mathrm{~min}$, and more NMP was added to yield a paste. The obtained paste was coated on graphite foil (Alfa Aesar, Karlsruhe, Germany) applying a doctor blading method. Subsequently, the NMP was removed by heating the electrodes at $40{ }^{\circ} \mathrm{C}$ under high vacuum for $24 \mathrm{~h}$. After drying, the amount of active material on the electrode was determined based on the weight of the electrodes.

\section{Preparation of zinc-organic hybrid batteries}

The batteries were manufactured in beaker-type cells using a two- or three-electrode setup. Zinc foil (in excess) was used as the anode, and a composite electrode was applied as the cathode; a $1 \mathrm{~m}$ zinc tetrafluoroborate hexahydrate solution served as the electrolyte. Electrochemical measurements were performed after an equilibration time of $1 \mathrm{~h}$. All experiments were carried out at room temperature in air. The charge/discharge capacities were determined based on the weight of $\mathbf{5}$ in the electrode.

\section{RESULTS AND DISCUSSION}

Compared with tetrathiafulvalene, which features two separate oneelectron oxidations, the $\pi$-extended derivative (exTTF) possesses a single two-electron oxidation. The redox potential of the second oxidation from a radical cation to a dication is shifted to a lower potential owing to the increased stability caused by the formation of an extended aromatic system and its planar low-energy conformation. ${ }^{20}$ The dication salt exhibits stability in air and is apparently a promising active material candidate for energy storage applications. The utilization of this redox-active moiety as an active cathode material led us to incorporate it into a polymeric poly(acetylene) backbone, thus enabling improved electron transfer through the conjugated polymeric backbone. $^{21}$

The 2-ethynyl(9,10-di(1,3-dithiol-2-ylidene)-9,10-dihydroanthracene) monomer (4) was synthesized in a straightforward three-step procedure, starting from commercially available 2-chloroanthraquinone (1), that is converted to 2-((trimethylsilyl)ethynyl)anthraquinone (2) in the first step (Scheme 1). After the deprotection of the ethynyl group under alkaline conditions, ${ }^{22}$ 2-ethynylanthraquinone (3) was transformed via the Horner-Wardsworth-Emmons reaction to the acetylene monomer. 4 exhibits poor solubility in organic solvents, which are commonly used for the metal-catalyzed polymerization of phenylacetylene derivative, but exhibits sufficient solubility in aprotic polar solvents, such as DMF or dimethylsulfoxide that are<smiles>O=C1c2ccccc2C(=O)c2cc(Cl)ccc21</smiles>

1

3

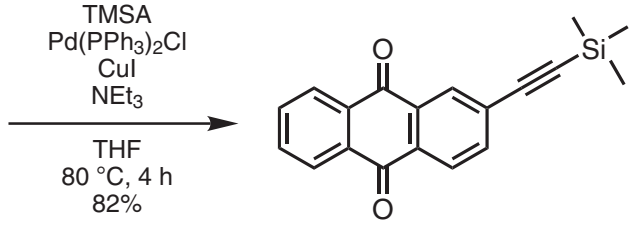

2<smiles>C#Cc1ccc2c(c1)C(=O)c1ccccc1C2=O</smiles>

3

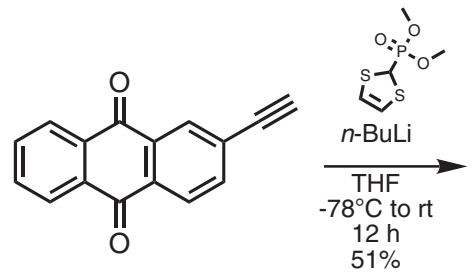<smiles>C#Cc1ccc2c(=C3SC=CS3)c3ccccc3c(=C3SC=CS3)c2c1</smiles>

4<smiles>CC(C)=C(C)c1ccc2c(=C3SC=CS3)c3ccccc3c(=C3SC=CS3)c2c1</smiles>

5

Scheme 1 Schematic representation of the synthesis of polymer 5. 
known to interfere with several catalyst systems. However, the polymerization of monomer 4 proceeded side-reaction free in DMF at room temperature with high conversions and with different rhodium-based catalysts, revealing its excellent functional group tolerance. ${ }^{19,23}$ The utilization of other solvents, such as chloroform or tetrahydrofuran, generally led to low degrees of conversion and precipitation of the polymer during the reaction owing to its low solubility. The best results were obtained with norbornadiene-based rhodium complexes because they featured an improved initiation efficiency. ${ }^{24}$ The polymers obtained by four different complexes were investigated in detail (Table 1). All catalysts led to polymers with low polydispersity indices in the range of 1.11 to 1.36 and molar masses in the range of $2.08 \times 10^{3}$ to $1.47 \times 10^{4} \mathrm{~g} \mathrm{~mol}^{-1}$, according to size exclusion chromatography (poly(styrene) standard) (see Supplementary Figures S1-S4). In particular, the quaternary catalyst system consisting of chloro(2,5-norbornadiene)rhodium(I) dimer, sodium methoxide, triphenylphosphine and $\mathrm{N}, \mathrm{N}$-dimethylaminopyridine, which is known to polymerize phenylacetylenes, led to polymers with the polydispersity index value as low as 1.11. All polymers obtained were insoluble in the common organic solvents used as electrolyte in batteries, such as organic carbonates or acetonitrile, but were slightly soluble in $\mathrm{N}, \mathrm{N}$-dimethylacetamide, enabling investigations of the ultraviolet-visible spectra of both monomer $\mathbf{4}$ and polymer 5. Both compounds featured two absorption maxima at $\sim 430$ and $370 \mathrm{~nm}$ (one of the polymers was slightly red shifted), further demonstrating that the 1,3-dithiol-2-ylidene functionalities do not interfere during the polymerization reaction (see Supplementary Figure S5). The electrochemical behavior of monomer 4 was examined in solution using cyclic voltammetry, and a $0.1 \mathrm{~m}$ solution of sodium tetrafluoroborate in DMF served as the electrolyte (Figure 1). The monomer underwent chemically reversible oxidation at $-0.03 \mathrm{~V}$ vs $\mathrm{Fc}$ $+/ F c$, in good agreement with the results from previous studies. ${ }^{24}$ The peak split between oxidation and re-reduction increased significantly with increasing scan rate, indicating a quasi-reversible electrochemical behavior that is derived from the large geometrical changes within the redox-active unit and the comparably slow kinetics unit during the redox reaction. ${ }^{25}$

In contrast, the electrochemical behavior of polymer $\mathbf{5}$ strongly differed under the same conditions. It featured chemically reversible

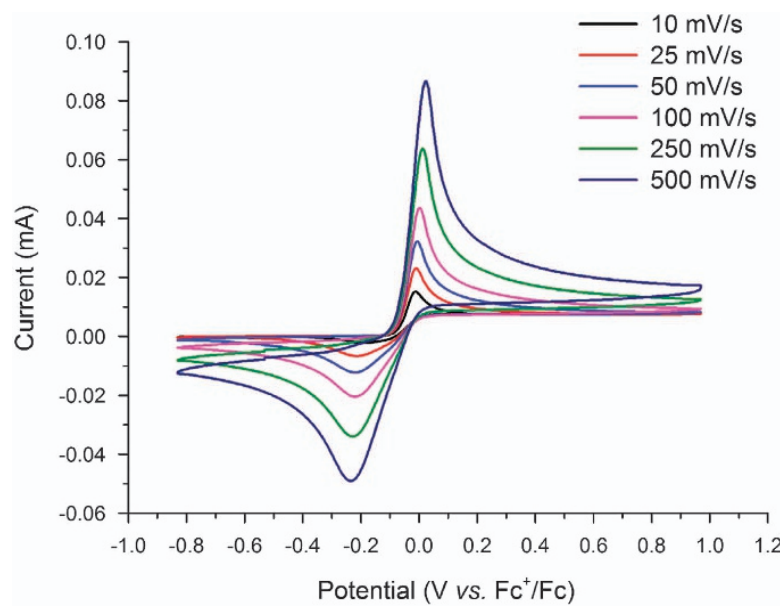

Figure $1 \mathrm{~A}$ cyclic voltammogram of monomer $4\left(1 \mathrm{mg} \mathrm{ml}^{-1}\right)$ in $\mathrm{N}, \mathrm{N}$ dimethylformamide containing $0.1 \mathrm{~m}$ sodium tetrafluoroborate at different scan rates of $10,25,50,100,250$ and $500 \mathrm{mV} \mathrm{s}^{-1}$. CE, Pt-wire; RE, $\mathrm{AgNO}_{3} / \mathrm{Ag}$, and the $\mathrm{Fc}^{+} / \mathrm{Fc}$ couple was added as an internal reference after the experiment (not shown here); WE, glassy carbon. oxidation at a similar potential, but instead of sharp and well-defined oxidation and re-reduction peaks, the polymer revealed very broad and undefined oxidation/re-reduction waves that spread over $1 \mathrm{~V}$ (see Supplementary Figure S6). This behavior is most likely owing to the continuous conjugation of all redox units because of the poly (acetylene) backbone (see Supplementary Figure S7).

This behavior led us to the examination of the electrochemistry of the polymer in the solid state. Therefore, polymer films of $\mathbf{5}$ were manufactured by drop-casting $50 \mu$ l of a solution of 5 in DMF $\left(1 \mathrm{mg} \mathrm{ml}^{-1}\right)$ onto a glassy carbon plate, and they were analyzed after the evaporation of the solvent under reduced pressure. Surprisingly, the polymer films in acetonitrile containing $0.1 \mathrm{M}$ sodium tetrafluoroborate feature defined chemically reversible oxidation and rereduction peaks at an average potential of $-0.07 \mathrm{~V} \mathrm{vs} \mathrm{Fc}^{+} / \mathrm{Fc}$, indicating a limited influence from the conjugated backbone on the
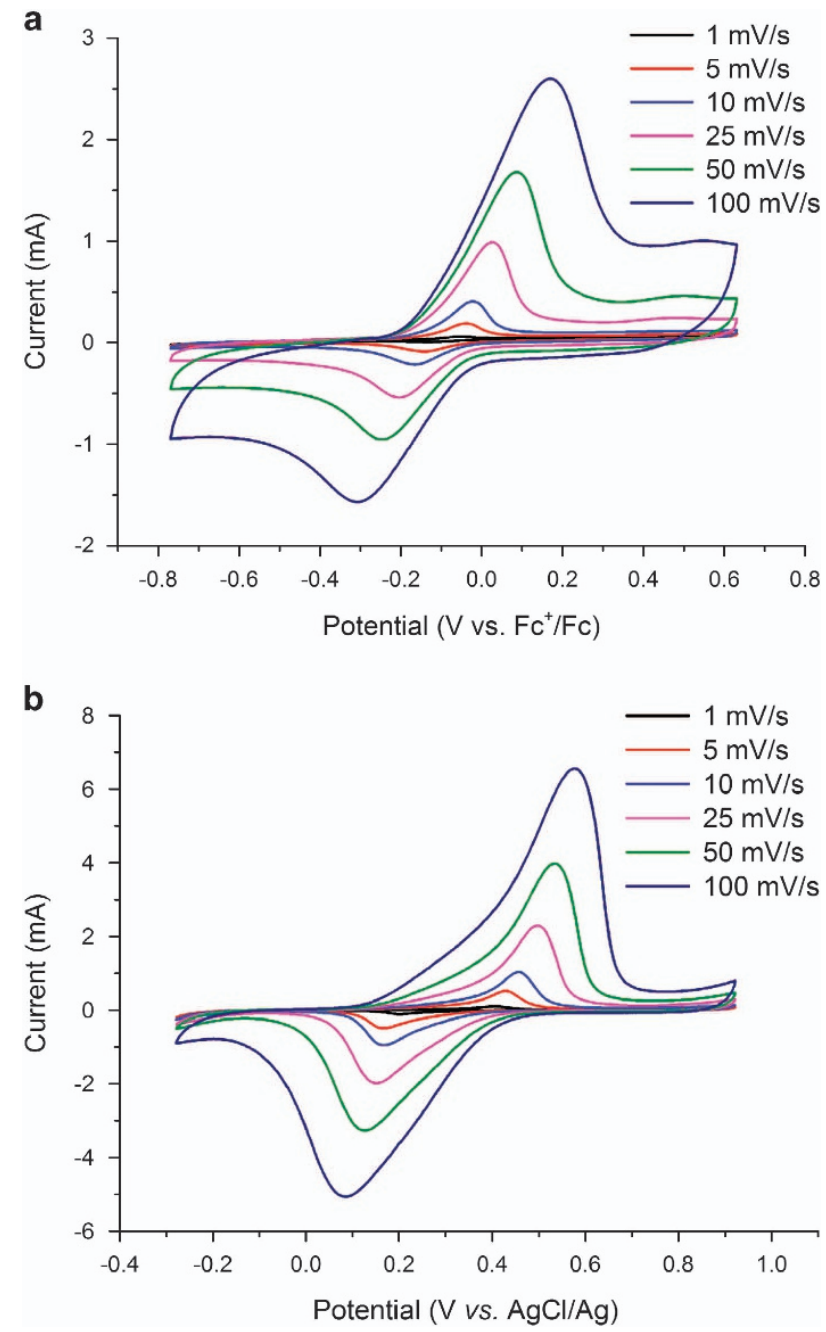

Figure 2 (a) A cyclic voltammogram of a film of polymer $5\left(\sim 0.05 \mathrm{mg} \mathrm{cm}^{-2}\right)$ processed by drop-casting a solution of $1 \mathrm{mg} \mathrm{ml}^{-1} 5$ in $\mathrm{N}, \mathrm{N}$ dimethylformamide (DMF), in acetonitrile containing $0.1 \mathrm{M}$ sodium tetrafluoroborate, at different scan rates of $1,5,10,25,50$ and $100 \mathrm{mV} \mathrm{s}^{-1}$. CE, coiled Pt-wire; $\mathrm{RE}, \mathrm{AgNO}_{3} / \mathrm{Ag}$, and the $\mathrm{Fc}^{+} / \mathrm{Fc}$ couple was added as an internal reference after the experiment (not shown here); WE, glassy carbon. (b) A cyclic voltammogram of a film of polymer $\mathbf{5}$ $\left(\sim 0.05 \mathrm{mg} \mathrm{cm}^{-2}\right)$, processed by drop-casting a solution of $1 \mathrm{mg} \mathrm{ml}^{-1} \mathbf{5}$ in DMF, in water containing $0.1 \mathrm{~m}$ sodium tetrafluoroborate, at different scan rates of $1,5,10,25,50$ and $100 \mathrm{mV} \mathrm{s}^{-1}$. 
redox-active units in the solid state (Figure $2 \mathrm{a}$ ). The peak split between the maxima of the oxidation and the re-reduction increased at higher scan rates and was $\sim 80 \mathrm{mV}$ at $1 \mathrm{mV} \mathrm{s}^{-1}$ and $\sim 400 \mathrm{mV}$ at $100 \mathrm{mV} \mathrm{s}^{-1}$. This is an indication of slow redox reaction kinetics. However, during cycling, the intensity of the redox signal decreased from cycle to cycle owing to the solubility of the cationic polymeric species in the electrolyte that led to a permanent loss in the capacity of the battery device. This solubility problem can be circumvented by using aqueous electrolytes. The cyclic voltammograms of polymer films made from polymer $\mathbf{5}$ on glassy carbon plates immersed in an aqueous $0.1 \mathrm{~m}$ sodium tetrafluoroborate solution featured a stable peak intensity over hundreds of cycles at an average potential of $0.11 \mathrm{~V}$ vs $\mathrm{AgCl} / \mathrm{Ag}$ and was accompanied by a large peak split even at very slow scan rates $\left(\sim 200 \mathrm{mV}\right.$ at $\left.1 \mathrm{mV} \mathrm{s}^{-1}\right)$ that only slightly increased at faster scan rates (Figure $2 \mathrm{~b}$ ). This redox behavior illustrates the stability and the insolubility of all of the redox states of the polymer in aqueous environments at neutral $\mathrm{pH}$ values.

The poor material loading of the polymer films, which was $\sim 0.05 \mathrm{mg} \mathrm{cm}^{-2}$ of active material, led to insufficient capacities for any practical application. Therefore, we investigated the electrochemical behavior of polymer $\mathbf{5}$ as the active material in composite electrodes. MWCNTs were chosen as a conductive additive because of their high surface area and their promising conductivity along with PVDF as a binding additive. The composite electrodes were manufactured in a suspension-based process, whereby a solution of polymer 5 and PVDF in NMP were mixed with MWCNTs in a mortar to yield a paste. The paste was then spread onto a graphite foil using a doctor blading method and subsequently dried at an elevated temperature and under reduced pressure. According to this procedure, electrodes with a coated area of $\sim 1 \mathrm{~cm}^{2}$ having different polymer/conductive additive/binder ratios were manufactured. Elemental analysis was utilized to investigate their homogeneity (see Supplementary Table S1), and scanning electron microscopy was employed to examine their surface morphologies (see Supplementary Figure S8). In particular, electrodes with ratios of $2 / 7 / 1(\mathrm{~m} / \mathrm{m} / \mathrm{m})$ and $1 / 1 / 0(\mathrm{~m} / \mathrm{m} / \mathrm{m})$ 5/MWCNT/PVDF were evaluated in detail. According to the scanning

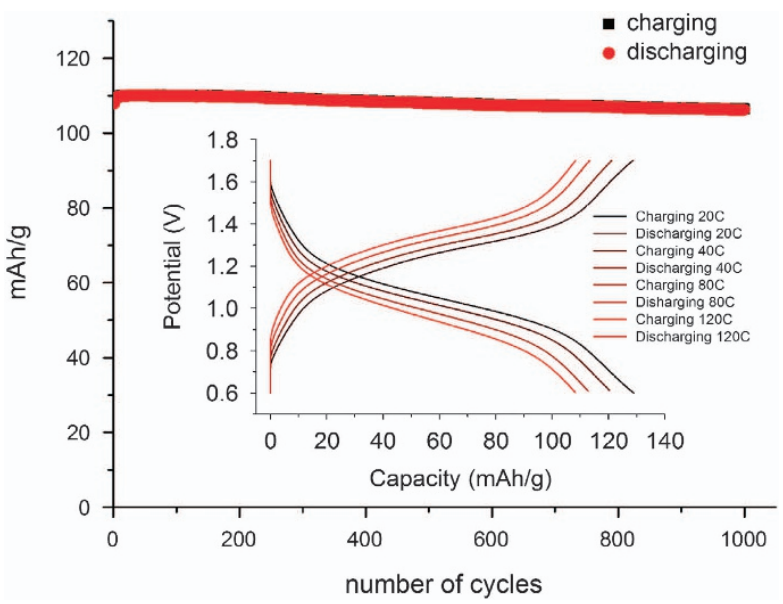

Figure 3 The capacity development during extended charge/discharge cycling of a zinc-organic hybrid battery (electrode composition: 20/70/10 m/ $\mathrm{m} / \mathrm{m}$ 5/MWCNT/PVDF) over 1000 cycles at $120 \mathrm{C}$, with $1 \mathrm{~m}$ aqueous zinc tetrafluoroborate solution as the electrolyte. Inset: The charge/discharge curves of a zinc-organic hybrid battery (electrode composition: 20/70/10 m/ $\mathrm{m} / \mathrm{m}$ 5/MWCNT/PVDF) at different charging/discharge speeds of 20, 40, 80 and $120 \mathrm{C}$, with $1 \mathrm{~m}$ aqueous zinc tetrafluoroborate solution as the electrolyte. MWCNT, multi-walled carbon nanotube; PVDF, poly(vinylidene fluoride). electron microscopy, both electrodes revealed a quite rough and porous surface consisting of a homogenous network of MWCNTs that were evenly coated by the redox-active polymer.

An increase in the amount of polymer, however, resulted in a lessfissured surface compared with the electrode with $20 \mathrm{wt} \%$ polymer that exhibited a pronounced microparticulate/microstructured surface. In addition, the electrodes featured a consistent polymer distribution over their entire surface area that was proven by the investigation of the sulfur content and the sulfur to carbon ratio of different electrode positions using elemental analysis. The material loading was determined on the basis of the weight of the electrode and resulted in $\sim 1.5 \mathrm{mg} \mathrm{cm}^{-2}$ and $\sim 5 \mathrm{mg} \mathrm{cm}^{-2}$ for the $20 \mathrm{wt} \%$ and $50 \mathrm{wt} \%$ electrodes, respectively.

For the application of these polymer-based composite electrodes as a cathode material in an aqueous organic battery, a suitable anode material that undergoes a reversible reduction in aqueous media and at a redox potential within the stable electrochemical operation window needs to be applied. This led us to investigate the $\mathrm{Zn}^{2+} / \mathrm{Zn}$ redox couple that exhibits a reversible redox reaction at $\sim-0.9 \mathrm{~V}$ vs $\mathrm{AgCl} / \mathrm{Ag}$ and has been successfully applied in zinc-organic batteries. ${ }^{26-29}$ The utilization of zinc foil that serves as both an anode material and a current collector in combination with an aqueous solution of a zinc salt leads, in principle, to a hybrid zinc-organic battery with a cell potential of $1.1 \mathrm{~V}$. This battery was assembled in a beaker-type cell using a composite cathode, a zinc foil anode and a $1 \mathrm{M}$ aqueous solution of zinc tetrafluoroborate hexahydrate as the electrolyte. The cyclic voltammogram of this battery, where the zinc foil was utilized as the anode and reference electrode simultaneously, revealed, at a scan rate of $10 \mathrm{mV} \mathrm{s}^{-1}$, an oxidation at $1.35 \mathrm{~V}$ and a re-reduction at $0.98 \mathrm{~V}$, and this is in good agreement with the behavior of the polymer film. This indicates that the additives of the composite electrode have minimal influence on the redox behavior (see Supplementary Figure S9).

The zinc-polymer battery with a composite electrode composed of $20 \mathrm{wt} \%$ active material exhibited a surprisingly high rate performance. The theoretical capacity of the battery is determined by the composite electrode $\left(133 \mathrm{mAh} \mathrm{g}^{-1}\right)$ because zinc is used in excess. The battery was charged/discharged at different speeds in the potential range between 0.6 and $1.7 \mathrm{~V}$. According to the cyclic voltammogram, the aqueous electrolyte was stable within this potential window and no gas evolution was visible at either electrode. At a charge/discharge speed of $20 \mathrm{C}$, which is equal to a full charge/discharge within $3 \mathrm{~min}$, the battery maintained a capacity of $128 \mathrm{mAh} \mathrm{g}^{-1}$ ( $96 \%$ material activity) and a coulombic efficiency of over 99\% (Figure 3, inset). The average charge and discharge potentials of the battery were 1.2 and $1.1 \mathrm{~V}$, respectively, in good agreement with the cyclic voltammogram.

An increase in the charge/discharge speed of up to $120 \mathrm{C}$ (equal to a full charge/discharge within $30 \mathrm{~s}$ ) led to only a minor decrease in the retained capacity $\left(111 \mathrm{mAh} \mathrm{g}^{-1} ; 83 \%\right.$ active material) at an excellent coulombic efficiency of over $99 \%$. At this charge/discharge speed, the average charge and discharge potentials were further separated to 1.4 and $0.9 \mathrm{~V}$, respectively. Furthermore, the lifetime of this hybrid zincorganic battery was examined at $120 \mathrm{C}$. After 1000 charge/discharge cycles, the battery still maintained a capacity of $105 \mathrm{mAh} \mathrm{g}^{-1}(79 \%$ material activity, $4 \%$ loss). However, the use of composite electrodes with only $20 \mathrm{wt} \%$ active material is not favorable for any real-world practical applications.

After decisive optimization of the electrode, composites with an active material content of $50 \mathrm{wt} \%$ polymer $(1 / 1 / 0, \mathrm{~m} / \mathrm{m} / \mathrm{m}$ $5 / \mathrm{MWCNT} / \mathrm{PVDF}$ ) were produced, and they were mechanically stable enough to serve as electrodes. These electrodes were investigated as a 

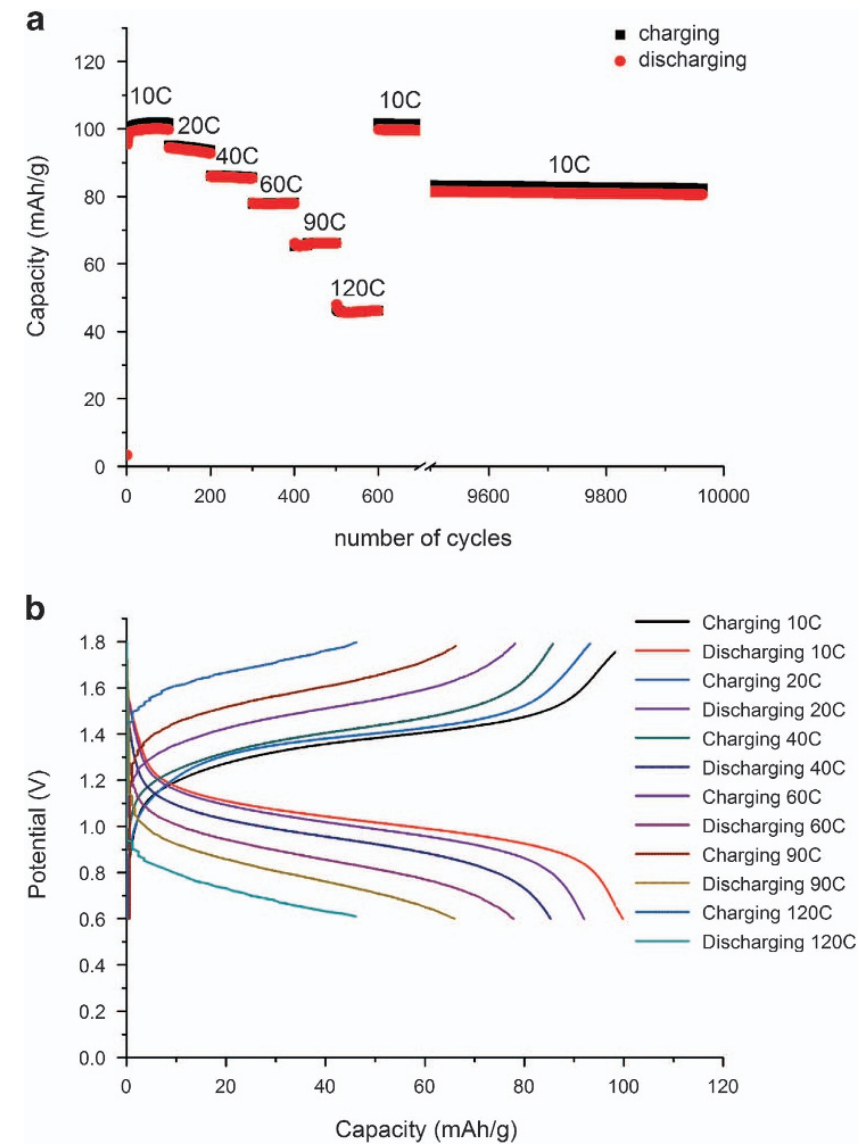

Figure 4 (a) The capacity development during extended charge/discharge cycling of a zinc-polymer hybrid battery (electrode composition: 1/1 m/m 5/MWCNT) over 10000 cycles; the first 600 cycles were at 10, 20, 40, 60, 90 and $120 \mathrm{C}$ for 100 cycles each, then 9600 cycles at $10 \mathrm{C}$ (the first 100 and the last 500 cycles are displayed). The electrolyte was $1 \mathrm{~m}$ aqueous zinc tetrafluoroborate solution. (b) Charge/discharge curves of the zinc-organic hybrid battery (electrode composition $1 / 1 \mathrm{~m} / \mathrm{m} \mathrm{5/MWCNT)}$ ) at different charging/discharge speeds of $10,20,40,60,90$ and $120 \mathrm{C}$, with $1 \mathrm{~m}$ aqueous zinc tetrafluoroborate solution as the electrolyte. MWCNT, multiwalled carbon nanotube.

cathode material in zinc hybrid batteries at different charge/discharge speeds using a $1 \mathrm{~m}$ zinc tetrafluoroborate hexahydrate solution as the electrolyte; compared with the electrode with $20 \%$ active material, their performance decreased. The batteries were charged/discharged in the potential window between $0.6 \mathrm{~V}$ and $1.7 \mathrm{~V}$ at 10, 20, 40, 60, 90 and $120 \mathrm{C}$ for 100 cycles at each speed, followed by 9400 cycles at $10 \mathrm{C}$, to investigate the rate performance and lifetime. The capacity of each cycle is displayed in Figure $4 \mathrm{a}$, and the corresponding charge/discharge curves of every 100th cycle of each speed are shown in Figure 4b. At a charge/discharge speed of $10 \mathrm{C}$ (full charge/discharge in $6 \mathrm{~min}$ ), a capacity of $100 \mathrm{mAh} \mathrm{g}^{-1}$ (75\% active material) was maintained, accompanied by an average charge/discharge plateau at $1.3 \mathrm{~V}$ for charging and $1.1 \mathrm{~V}$ for discharging. The capacity dropped constantly with increasing charge/discharge speed and reached $47 \mathrm{mAh} \mathrm{g}^{-1}$ (35\% material activity) at a charge/discharge speed of $120 \mathrm{C}$. Furthermore, as shown in Figure 4b, with increasing speed, the average charge/ discharge plateau potential was increased/decreased to such an extent that, at a speed of $120 \mathrm{C}$, no distinct plateaus were visible. This phenomenon is possibly caused by limited electron transfer within the composite electrode. Nevertheless, in each of the 100 cycles the capacity remained constant, and the charge/discharge process featured a coulombic efficiency over $97 \%$. To examine the lifetime of this zincorganic hybrid battery, it was charged/discharged for an additional 9600 cycles at a speed of $10 \mathrm{C}$. After a total of 10000 cycles, the battery revealed a capacity of $81 \mathrm{mAh} \mathrm{g}^{-1}$ (61\% material activity, 14\% loss), indicating that the redox polymer in the aqueous electrolyte under aerobic conditions possessed excellent stability. Owing to the slightly acidic $\mathrm{pH}$ of the electrolyte ( $\sim \mathrm{pH} 6)$, neither the oxidation of the zinc foil nor the formation of zinc dendrites could be observed. In addition, the redox reaction seems to be side-reaction free because, even at very low speeds of $0.1 \mathrm{C}$ (complete charging/discharging within $10 \mathrm{~h}$ ), a capacity of $106 \mathrm{mAh} \mathrm{g}^{-1}$ was reached that remained stable for over 50 subsequent charge/discharge cycles (Supplementary Figure S10). To rule out the influence of the conductive additive and the conjugated poly(phenylacetylene) backbone on the capacity of the battery, electrodes were investigated using poly(phenylacetylene) as the active material $(1 / 1 \mathrm{~m} / \mathrm{m}$, poly(phenylacetylene)/MWCNT). As expected, the conductive additive and the conjugated polymer backbone had negligible influence on the capacity that was in the range of $10 \mathrm{mAh} \mathrm{g}^{-1}$ at $0.1 \mathrm{C}$ and $0.25 \mathrm{mAh} \mathrm{g}^{-1}$ at $120 \mathrm{C}$ (Supplementary Figure S11). Furthermore, neither the exTTF nor the zinc redox couples are sensitive to oxygen, allowing for operation of this zincorganic battery in air atmosphere without degassing the electrolyte.

\section{CONCLUSION}

The polymerization of 2-ethynyl(exTTF) with various Rh catalysts led to redox-active polymers with very low polydispersity index values. The excellent functional group tolerance of the Rh catalysts enabled the preparation of polymers with a conjugated backbone and exTTF units as substituents. Films of these polymers on glassy carbon feature, owing to the special molecular structure of the exTTF unit, one chemically reversible two-electron oxidation at $-0.07 \mathrm{~V}$ vs $\mathrm{Fc}^{+} / \mathrm{Fc}$ in acetonitrile and at $0.35 \mathrm{~V}$ vs $\mathrm{AgCl} / \mathrm{Ag}$ in aqueous electrolytes. The slight solubility of the oxidized polymer in organic electrolytes directed us to investigate the use of polymer $\mathbf{5}$ as a cathode-active material in water-based secondary batteries. Owing to the compact molecular structure, the polymer had a theoretical capacity of $133 \mathrm{mAh} \mathrm{g}^{-1}$. Composite materials were used as the cathode to maintain high active material loading, and elemental zinc foil was applied as the anode, leading to an average battery voltage of $1.1 \mathrm{~V}$. The amount of active material in the composite electrode was varied, and its influence on the battery performance was investigated in detail. At a loading of $20 \mathrm{wt} \%$ active material, the battery could be charged/discharged with a high speed of $120 \mathrm{C}$ (full charge/discharge in $30 \mathrm{~s}$ ) and exhibited a material activity of $83 \%\left(111 \mathrm{mAh} \mathrm{g}^{-1}\right)$. Furthermore, the battery featured highly promising lifetimes: after 1000 charge/discharge cycles at $120 \mathrm{C}$, a material activity of $79 \%\left(105 \mathrm{mAh} \mathrm{g}^{-1}, 4 \%\right.$ loss $)$ was maintained. Batteries with a higher amount of active material (50 wt $\%$ ) exhibited a poorer rate performance, but could still be charged/ discharged at a speed of $10 \mathrm{C}$ and exhibited a promising material activity of $75 \%\left(100 \mathrm{mAh} \mathrm{g}^{-1}\right)$. Higher charge/discharge speeds led to a decrease in the capacity. Nonetheless, the battery could still be charged/discharged at $120 \mathrm{C}$ while maintaining a capacity of $47 \mathrm{mAh} \mathrm{g}^{-1}$ (35\% material activity). Furthermore, the battery features an ultra-long lifetime. After 10000 charge/discharge cycles, a capacity of $81 \mathrm{mAh} \mathrm{g}^{-1}$ (61\% material activity) was reached. These long life cycles and the simple fabrication techniques are enabled by the superior chemical stability of the polymeric cathode as well as the insensitivity of the fabricated batteries to atmospheric oxygen. 


\section{CONFLICT OF INTEREST}

The authors declare no conflict of interest.

\section{ACKNOWLEDGEMENTS}

We thank the European Social Fund (ESF), the Thüringer Aufbaubank (TAB), the Thuringian Ministry for Economic Affairs, Science and Digital Society (TMWWdG) and the Federal Ministry of Education and Research Germany (BMBF, PhoNa project in the framework of the excellence program 'Spitzenforschung \& Innovation in den Neuen Ländern') for financial support.

1 Nishide, H. \& Oyaizu, K. Toward flexible batteries. Science 319, 737-738 (2008).

2 Nyholm, L., Nyström, G., Mihranyan, A. \& Strømme, M. Toward flexible polymer and paper-based energy storage devices. Adv. Mater. 23, 3751-3769 (2011).

3 Poizot, P. \& Dolhem, F. Clean energy new deal for a sustainable world: from non- $\mathrm{CO}_{2}$ generating energy sources to greener electrochemical storage devices. Energy Environ. Sci. 4, 2003-2019 (2011).

4 Vadehra, G. S., Maloney, R. P., Garcia-Garibay, M. A. \& Dunn, B. Naphthalene diimide based materials with adjustable redox potentials: evaluation for organic lithium-ion batteries. Chem. Mater. 26, 7151-7157 (2014).

5 Janoschka, T., Hager, M. D. \& Schubert, U. S. Powering up the future: radical polymers for battery applications. Adv. Mater. 24, 6397-6409 (2012).

6 Häupler, B., Wild, A. \& Schubert, U. S. Carbonyls: powerful organic materials for secondary batteries. Adv. Energy Mater. 5, 1402034 (2015).

7 Song, Z. \& Zhou, H. Towards sustainable and versatile energy storage devices: an overview of organic electrode materials. Energy Environ. Sci. 6, 2280-2301 (2013).

8 Nishide, H., Iwasa, S., Pu, Y. J., Suga, T., Nakahara, K. \& Satoh, M. Organic radical battery: nitroxide polymers as a cathode-active material. Electrochim. Acta 50, 827-831 (2004).

9 Suga, T., Ohshiro, H., Sugita, S., Oyaizu, K. \& Nishide, H. Emerging N-type redox-active radical polymer for a totally organic polymer-based rechargeable battery. Adv. Mater. 21, 1627-1630 (2009).

10 Häupler, B., Hagemann, T., Friebe, C., Wild, A. \& Schubert, U. S. Dithiophenedionecontaining polymers for battery application. ACS Appl. Mater Interfaces 7 , 3473-3479 (2015).

11 Kawai, T., Oyaizu, K. \& Nishide, H. High-density and robust charge storage with poly (anthraquinone-substituted norbornene) for organic electrode-active materials in polymer-air secondary batteries. Macromolecules 48, 2429-2434 (2015).

12 Häupler, B., Burges, R., Friebe, C., Janoschka, T., Schmidt, D., Wild, A. \& Schubert, U. S. Poly(exTTF): a novel redox-active polymer as active material for Li-organic batteries. Macromol. Rapid Commun. 35, 1367-1371 (2014).

13 Speer, M. E., Kolek, M., Jassoy, J. J., Heine, J., Winter, M., Bieker, P. M. \& Esser, B. Thianthrene-functionalized polynorbornenes as high-voltage materials for organic cathode-based dual-ion batteries. Chem. Commun. 51, 15261-15264 (2015).

14 Oyaizu, K., Ando, Y., Konishi, H. \& Nishide, H. Nernstian adsorbate-like bulk layer of organic radical polymers for high-density charge storage purposes. J. Am. Chem. Soc. 130, 14459-14461 (2008).

15 Li, W., Dahn, J. R. \& Wainwright, D. S. Rechargeable lithium batteries with aqueous electrolytes. Science 264, 1115-1118 (1994).
16 Li, W., McKinnon, W. R. \& Dahn, J. R. Lithium intercalation from aqueous solutions. J. Electrochem. Soc. 141, 2310-2316 (1994).

17 Oyaizu, K., Choi, W. \& Nishide, H. Functionalization of poly(4-chloromethylstyrene) with anthraquinone pendants for organic anode-active materials. Polymer Adv. Tech. 22, 1242-1247 (2011).

18 Schmidt, D., Häupler, B., Hager, M. D. \& Schubert, U. S. Synthesis and characterization of new redox-active polymers based on 10-(1,3-dithiol-2-ylidene)anthracen-9(10H)-one derivatives as promising materials for organic electronics. Polymer 53, 2517-2523 (2015).

19 Liu, J., Lam, J. W. Y. \& Tang, B. Z. Acetylenic polymers: syntheses, structures, and functions. Chem. Rev. 109, 5799-5867 (2009).

20 Brunetti, F. G., Lopez, J. L., Atienza, C. \& Martin, N. pi-Extended TTF: a versatile molecule for organic electronics. J. Mater. Chem. 22, 4188-4205 (2012).

21 Liang, Y., Chen, Z., Jin, Y., Rong, Y., Facchetti, A. \& Yao, Y. Heavily n-dopable $\pi$-conjugated redox polymers with ultrafast energy storage capability. J. Am. Chem. Soc. 137, 4956-4959 (2015).

22 Oyaizu, K., Niibori, Y., Takahashi, A. \& Nishide, H. BODIPY-sensitized photocharging of anthraquinone-populated polymer layers for organic photorechargeable air battery. J. Inorg. Organomet. P 23, 243-250 (2013).

23 Shiotsuki, M., Sanda, F. \& Masuda, T. Polymerization of substituted acetylenes and features of the formed polymers. Polym. Chem. 2, 1044-1058 (2011).

24 Molina-Ontoria, A., García, R., Gouloumis, A., Giacalone, F., Torres, M. R. \& Martín, N. A straightforward electroactive $\pi$-extended tetrathiafulvalene (exTTF) building block. Eur. J. Org. Chem. 2012, 3581-3586 (2012).

25 Gruhn, N. E., Macias-Ruvalcaba, N. A. \& Evans, D. H. Studies of potential inversion in an extended tetrathiafulvalene. Langmuir 22, 10683-10688 (2006).

26 Koshika, K., Sano, N., Oyaizu, K. \& Nishide, H. An aqueous, electrolyte-type, rechargeable device utilizing a hydrophilic radical polymer-cathode. Macromol. Chem. Phys. 210, 1989-1995 (2009).

27 Koshika, K., Sano, N., Oyaizu, K. \& Nishide, H. An ultrafast chargeable polymer electrode based on the combination of nitroxide radical and aqueous electrolyte. Chem. Commun. 45, 836-838 (2009).

28 Zhang, B., Liu, Y., Wu, X., Yang, Y., Chang, Z., Wen, Z. \& Wu, Y. An aqueous rechargeable battery based on zinc anode and $\mathrm{Na}_{0} .{ }_{95} \mathrm{MnO}_{2}$. Chem. Commun. 50, 1209-1211 (2014)

29 Ghanbari, K., Mousavi, M. F., Shamsipur, M. \& Karami, H. Synthesis of polyaniline/ graphite composite as a cathode of $\mathrm{Zn}$-polyaniline rechargeable battery. J. Power Sources 170, 513-519 (2007).

(i) This work is licensed under a Creative Commons Attribution 4.0 International License. The images or other third party material in this article are included in the article's Creative Commons license, unless indicated otherwise in the credit line; if the material is not included under the Creative Commons license, users will need to obtain permission from the license holder to reproduce the material. To view a copy of this license, visit http:// creativecommons.org/licenses/by/4.0/

(C) The Author(s) 2016

Supplementary Information accompanies the paper on the NPG Asia Materials website (http://www.nature.com/am) 